\title{
Computer Modeling Algorithm Development of the Innovative Project Effectiveness Evaluation
}

\author{
${ }^{*}$ Elena Makarova, ${ }^{\dagger}$ Anna Firsova \\ * Southern Federal University, Rostov-on-Don, Russian Federation \\ *elmakarova@sfedu.ru \\ ${ }^{\dagger}$ Saratov State University, Saratov, Russian Federation \\ †a.firsova@rambler.ru
}

\begin{abstract}
The main purpose of this research is to develop methodological support and economic and mathematical tools for managing and evaluating the effectiveness of innovative projects based on binomial models of real options. The subject of the study is a computer program algorithm for using the binomial model of real options and a model for phased risk assessment of innovative projects portfolios on this basis. The scientific hypothesis of the research is based on the need for the economic and mathematical toolkit developed for the innovative project and allows increasing the accuracy of the assessment when analyzing projects, which is very important when it comes to innovative projects with a high degree of uncertainty. The novelty of the approach consists of the possibility for the consideration of innovative projects from the perspective of multi-stage and multi-scenarios, as well as the use of binomial models using the theory of real options and a phased risk assessment model for innovative project portfolios and their implementation as a software product. The authors proposed technical and economic project efficiency evaluation of the market potential of the project results with a high level of probability in the form of a software package. The results of the study have empirical value for the research results, and application in practice of analyzing investment projects will help improve the accuracy of estimates and justify the feasibility of investor participation in innovative projects.
\end{abstract}

Index Terms-Computer Program Algorithm, Innovation Project, Mathematical Modeling, Real Options Method, Project Investment, Binomial Model, Project Efficiency Evaluation.

\section{INTRODUCTION}

In the modern system of economic relations, special attention is paid to innovative activities in general and innovative projects in particular. The result of such activity is a specific innovation, innovative product, service or a private form of organization and management of the innovation process. The goal of the innovation project is to create a new or change the existing system - technical, technological, informational, social, economic, organizational, and achieve, as a result of reducing the costs of resources (production, financial, labor), a radical improvement in the quality of products, services and high commercial effect.

The result of the development of an innovative project is a document that includes a detailed description of the innovative product, the rationale for its viability, the need, the possibility and form of attracting investment, and taking into account the organizational and legal aspects of its promotion.

The sequence of actions based on technical and economic calculations aimed at achieving the investment goal, increasing the wealth of shareholders or business owners due to the growth of its value stimulates the adoption of investment and financial decisions on the feasibility of financing the selected innovative project.

Since the introduction of innovative products on the market, as a rule, requires investment, it is necessary to justify the feasibility of investing money and the possibility of profit from innovation commercialization. That is why the main goal of the research part of the project is to prove that the idea is not only innovative, but will be accepted by the market.

The currently existing toolkit for evaluating the effectiveness of innovative projects based on quantitative analysis allows making informed decisions about making investments. But the application of traditional methods of economic valuation is associated with a number of assumptions. For example, the methods of analyzing discounted cash flows (DCF) and net present value (NPV) suggest that the structure and cost of capital, as well as environmental conditions, do not change throughout the life cycle of an investment innovation project.

In practice, the uncertainty under which an innovative project is being implemented is an integral component of exogenous environmental factors in the implementation of most innovative projects and makes adjustments to their results and progress. The indicated rigidity of traditional methods leads to an underestimation and rejection of possible promising innovative projects, so it is advisable to evaluate their efficiency and support financial and investment decisions with algorithms and mathematical tools. Detailed analyzing of investing innovative projects provide the possibility of changing or refusing to implement an investment project at various stages of its implementation, as a process of creating and launching an innovative product on the market.

\section{TheORETICAL ANALYSis}

In the scientific literature, there are several basic approaches that make up the theoretical basis for research on management processes and evaluation of the effectiveness of innovation projects and the method of real options.

General theoretical and methodological approaches of innovative projects management based on traditional methods of analyzing their effectiveness are widely and fully disclosed in the researches of Russian and foreign scientists: V. M. Anshina, V. L. Barancheeva, A. A. Dagaeva, 
of the research is to develop methodological support and

N. I. Ivanova, L. K. Gapenski, S. V. Valdaytseva, A. Hamilton, G. Sabato, B. Santo, U. Sharp and others. The most widely used and recommended tool for assessing the impact of risk and uncertainty on project results is the adjustment of the discount rate, sensitivity analysis, the method scenarios, Monte Carlo method and method of fuzzy sets.

Problems of innovative projects management, including the construction of an effective organizational structure for project management are considered in the researches of T. M. Bronnikova, I. I. Mazur, V. D. Shapiro, S. A. Titova, V. V. Voropaeva and etc.

The concept of using real options during investment projects evaluation has been studied for about 30 years, first appearing in the works of S. Myers (1977) [1]. Real options have been thoroughly studied and described by P. Boehr, R. McGrath, J. Rosenberger, and a number of other foreign scientists. For the evaluation of the value of real options, the formulas of F. Black and M. Scholes (1973) were initially used to evaluate the value of financial options.

The application of the mathematical apparatus for calculating the cost of options using the Black-Scholes Option Pricing Model and the binomial model was considered in detail by R. Braeley, S. Myers "Principles of Corporate Finance", A. Damodaran "Investment valuation. Tools and methods for assessing any assets", promoting this method among practitioners on the basis of criticism of the NPV. Also, the vector of foreign studies was the adaptation of the methodical apparatus for evaluating financial options for the selection of investment projects.

It is noteworthy that the European literature also notes that the complexity of accounting for the uncertainty in the NPV indicator in the form of a risk-adjusted discount rate (especially for long-term investment projects, which also include radical innovative projects) was the explanation for the decline in long-term investments in a number of economies in Western European countries in the 1980s, 1990s.

The theory of real options has also been developed in Russia in the early 2000s, in particular, in the works of N. Bruslanov, M. A. Kanev, D. Y. Khomutsky, M. V. Lychagin, A. K. Pirogov, Y. Sysoev, A. V. Vorontsovsky etc.

In Russian researches, theoretical issues are well developed in the classification of real options and the need for their application to the analysis of projects. However, the issues of structuring real options throughout the life cycle of the innovation project, the use of binomial models in assessing the effectiveness and risks of implementing innovative projects and the methodology for modeling the evaluation characteristics of innovative projects at the current stage have not been adequately studied [2].

Studies in this direction are developing and are of some practical interest. The expected results of the project have no analogues in Russian and foreign science, they will complement the methods of assessing the effectiveness of innovative projects and can be presented as achievements of Russian science in the field of investment research and innovative development in the Russian conditions. The aim economic and mathematical tools for managing and evaluating the effectiveness of innovative projects based on binomial models of real options.

\section{ReseARCH Methodology}

\section{A. Net Present Value Methodology}

By decomposing the investment decisions at the stage, it is possible to structure various real options in the innovative project, allowing the project management in the future to make flexible management decisions at each stage of the project, based on the incoming information. This allows creating additional project value compared to options based on the analysis of NPV and DCF, not taking into account the possibility of using real options.

$$
N P V=\sum_{t=0}^{n} D C F_{i}=\sum_{t=0}^{n} \frac{C F_{i}}{(1+R)^{i}}=\sum_{t=0}^{n} \frac{S_{i}-K_{i}}{(1+R)^{i}},
$$

where $N P V$ - net present value of the innovative project; $D C F_{i}$ - discounted cash flow in $i$ period; $C F_{i}$ - cash flow in $i$ period; $S_{i}$ - revenues of performed project in $i$ period; $K_{i}-$ expenses of performed project in $i$ period; $r$-discount rate.

In the framework of traditional financial planning, the growth of a company is considered mainly from the perspective of endogenous problems of providing the necessary funds, but this is not enough to build an effective business strategy. Modern models for assessing the value of the company and managing corporate finance form an idea of the characteristics of the growth of the company from the standpoint of the multidimensionality of the exogenous environment. In recent decades, the main idea of corporate management has been the cost-based approach to company Value Based Management (VBM) in accordance with which the main goal of a business is to maximize its value and cost [3].

Value Based Management (VBM) methodology is aimed at quality strategic and operational decisions at all levels of the organization by focusing the efforts of all decision makers on key cost factors of innovative project. Out of the whole set of alternative target functions within the framework of the VBM concept, the maximization of the project value is selected. The value of the project is determined by its discounted future cash flows, and new value is created only when the organizations receive such a return on invested capital that exceeds the cost of raising capital.

The motive for implementing innovative projects and the priority goal of financing innovation is the growth of the company's value. The main objective of the corporate financial strategy is the development of an optimal project portfolio for value growth and its correlation with the level of strategic ambitions of the organization in the field of innovation. At the same time, the presence of a stable net profit, as well as a positive NPV, does not mean an increase in the value of the company as a result of the implementation of an innovative project. The project portfolio and company may lose value and become less attractive for investment. 


\section{B. Real Option Methodology: Black-Scholes Option Pricing Model}

Black-Scholes option pricing model [4] is a model that determines the theoretical price of European options, implying that if the underlying asset is traded on the market, then the price of the option on it is implicitly set by the market itself. This model has become widespread in practice and, among other things, can also be used to evaluate innovative projects, including the valuation of equity of financially dependent organizations.

The real options methodology provides managers with the opportunity to plan and manage strategic investments, being a hedging tool for a portfolio that includes investment in various high-risk innovative projects. But still, the main goal of the real options toolkit is not risk insurance, but maximizing the growth of the project costs.

These strategic prospects associated with the manager's active position are taken into account using the real option valuation (ROV) method. Real options are always conditional investments: the opportunities inherent in the project are realized only under certain conditions. Real options are evaluated using the binomial tree method based on a riskneutral approach [5].

The price of a financial option is summed up as a result of the joint action of the properties of the underlying stock of the option parameters, the main quantitative characteristics of the innovation project evaluation at which are the expected cash flow, expenses for the acquisition of innovative project funds, the period during which you can decide on the start of the project, uncertainty (level variance), the time value of money, the dividend rate for the underlying stock. The first four factors are most important for determining the price of an option. The other two are less significant, although the dividend rate may be significant in the case of high-yield stocks. The relationship between the parameters and the option price is expressed by the formulas:

$$
\begin{gathered}
C=p N\left(d_{1}\right)-s e^{-r t} N\left(d_{2}\right), \\
d_{1}=\frac{\ln \frac{p}{s}+\left(r+\frac{v^{2}}{2}\right) t}{v \sqrt{t}}, \\
d_{2}=d_{1}-v \sqrt{t},
\end{gathered}
$$

where $p-$ the expected cash flow; $s$ - the cost of acquiring funds for an innovative project; $t$ - the period during which it is possible to decide on the start of the project; $r$ - the time value of money; $\nu$ - uncertainty (level of dispersion); $N(d)-$ the normal cumulative probability density function.

To understand the essence of this model, it can be divided into two parts. The first part $p N(d 1)$ reflects the expected profit from the implementation of the innovation project. The calculation is made by multiplying the cost of the cash flows of the project $\mathrm{p}$ by the rate of change of the premium on the call option with respect to the change in the price of the underlying asset $N(d 1)$. The second part of the $s e^{-r t} N(d 2)$ model gives the present value of the investment. The objective market price of a call option is determined by subtracting the second part of the formula from the first.

The modified Black-Scholes formula makes it possible to take into account not only the uncertainty of the external environment of the project, but also the internal, when evaluating an investment innovative project. The advantage of using models of real options when evaluating investment projects is determined by the fact that the cost is often a variable, which depends on a number of external and internal conditions in relation to the production and financial characteristics of the project. It is such variables that are advisable to evaluate using the optional pricing technique. Considering real options in the valuation in this way, it is possible to eliminate the disadvantages of the discounted cash flow model [6].

However, it should be noted that option pricing models are not a substitute for traditional approaches to assessing the value of investment projects. Rather, they are an addition that makes it possible to take into account some aspects inaccessible to such a method as the method of net present value.

\section{Binominal Model Methodology: Cox-Ross-Rubinstein Option Pricing Model}

The simplest model with discrete values of asset prices (discrete time) is the so-called Cox-Ross-Rubinstein (CRR) model or the "binominal model" [7]. The CoxRoss-Rubinstein model played an exceptional role in the development and establishment of financial mathematics. It served as the basis for the construction of various theories of the real option market. The appearance of the model served as the starting point for the development of research in the application of modern stochastic analysis methods in the mathematical theory of finance.

The price of the option changes according to the "rise-fall" rule by a fixed amount, and what exactly happens, the rise or fall depends on the case. Today it is the main discrete model in the financial market. Its value lies also in the fact that the well-known continuous Black-Scholes model is a limiting case for it. The Cox-Ross-Rubinstein model is a fairly simple numerical way to model future price movements. The essence of such modeling is to divide the time remaining before expiration into $\mathrm{N}$ steps under the assumption that the price of the underlying asset at each step can either move up a certain amount with probability $\mathrm{p}$ or down, also at a certain amount with a probability $q=1-p$.

According to the binomial pricing model, the Call option (or Put option) can take one of two values: either $u$ is the maximum value, or $d$ is the minimum value. Next, formulas come into play, the main of which is the following:

$$
\begin{gathered}
C=\frac{p-d}{p} \times \frac{u-k}{u-d} \times S, \\
d=\frac{D}{S}, \quad u=\frac{U}{S}, \quad k=\frac{K}{S}, \quad p=(1+R)^{t},
\end{gathered}
$$




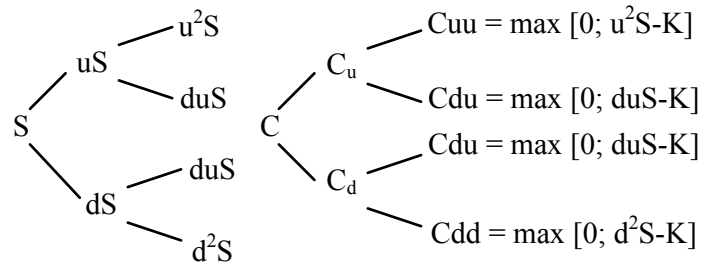

Fig. 1. Algorithm diagram of a binomial model for innovative project evaluating: $a$ - tree of present value of cash flows created in case of investment in the project today; $b$-option value tree.

where $S$ - present value of cash flows created in case of investment in the project today; $K$ - expenses incurred at the start of the project (investment costs); $R$ - required rate of return or risk-free rate of financial market; $t$ - time from the purchase of an option to its exercise (measured in years).

The common formula for evaluating multi-period binomial option pricing model is:

$$
\begin{gathered}
C=\frac{\sum_{i=0}^{n} \frac{n !}{i !(n-i) !} p^{i}(1-p)^{n-i}\left[u^{i} d^{n-i} S-K\right]}{r^{n}}, \\
p=\frac{(r-d)}{(u-d)},
\end{gathered}
$$

where $S$ (base asset value) - present value of cash flows created in case of investment in the project today; $K$ (option exercise price) - expenses incurred at the start of the project (investment costs). It is advisable to execute the option if $S>K ; R$ (required rate of return) - risk-free rate (yield on state long-term treasury bonds, adjusted for the specifics of the macroeconomic situation in the country); $i$ - the number of times the price rises with the pace $u ;(n-i)$ - the number of times the price drops at a pace $d ; n$ - number of periods into which the time interval remaining until the exercise of the option is divided.

The model uses the parameters of increasing and decreasing the value of the underlying asset $u$ and $d$, where $u$-increase, and $d$-decrease in the market value of the underlying asset, depending on the time factor during which changes in the rate of the underlying asset and its standard deviation can be observed [8].

Considering the above-mentioned problem of the lack of high-quality databases for innovative projects, for the correct use of mathematical statistics and probability theory, it is advisable to use the apparatus of fuzzy sets to obtain the correct parameter values. Without dwelling on this tool in detail, we note that it allows correct working with such important qualitative data as expert judgment.

\section{RESULTS}

Any investment project should be justified by feasibility study. These features determine the analysis of innovative projects from the perspective of multi-stage and multifunctionality design - dividing the implementation of the project into logical stages, and the transition to each subsequent stage of the project is directly related to the effectiveness of the previous one, and each stage can result in both success and loss. Project management makes decisions at the end of each stage: to develop, stop or postpone investment in the innovation project, taking into account the stages and uncertainties that affect the assessment of the overall economic efficiency of the project [9].

The main stages of innovation project are as follows.

1) Each innovation project must go through a scienceproduction-consumption cycle. The idea of an innovative project should have a basis in the form of scientific and marketing research, as well as production, should be tailored to the consumer and rely on scientific developments.

2) Difficulty in predicting results and, as a result, increased risks. The emergence of the new is always associated with a high risk of rejection by society. Conservatism in this regard is inherent not only to most of society, but to most Russian Federation production facilities that are not able to perceive innovations even technically. The probability of obtaining positive results, depending on the type and nature of innovative research, ranges from 5 to $90 \%$.

3) Development and implementation of an innovative project is a creative and unique task. Therefore, much depends on the enthusiasm and personal interest of the performers. An analysis of the causes of failure of innovative projects showed that a common reason for these failures is project management by ordinary hired managers who had the only motivation in the form of money.

4) Organization of work of project participants. The presence of free will and high motivation of the project participants makes the usual organization of labor and the creation of labor discipline inappropriate. Therefore, an adequate approach to the choice of management style by managers is necessary.

5) Lack of familiar standards for an innovative project. Even the clearest design concept can undergo major changes in the development process [10].

In this situation computer program development for the evaluation and modeling of the innovative projects effectiveness using binomial models will be helpful to use in financial management sector for a more accurate multipricing of innovative projects compared to existing methods. The general computer modeling algorithm development of the innovative project effectiveness evaluation based on real options in the form of a binary tree is presented on Fig. 2.

In most innovative projects, there are basic options, so Fig. 3 shows an example of a simple four-stage decision tree and in Fig. 4 there is a time-line: the first decision is made when starting an innovation project; a later choice is made at operational stages 1-3 during the development of the innovation project [11]. Between these elections, innovation 


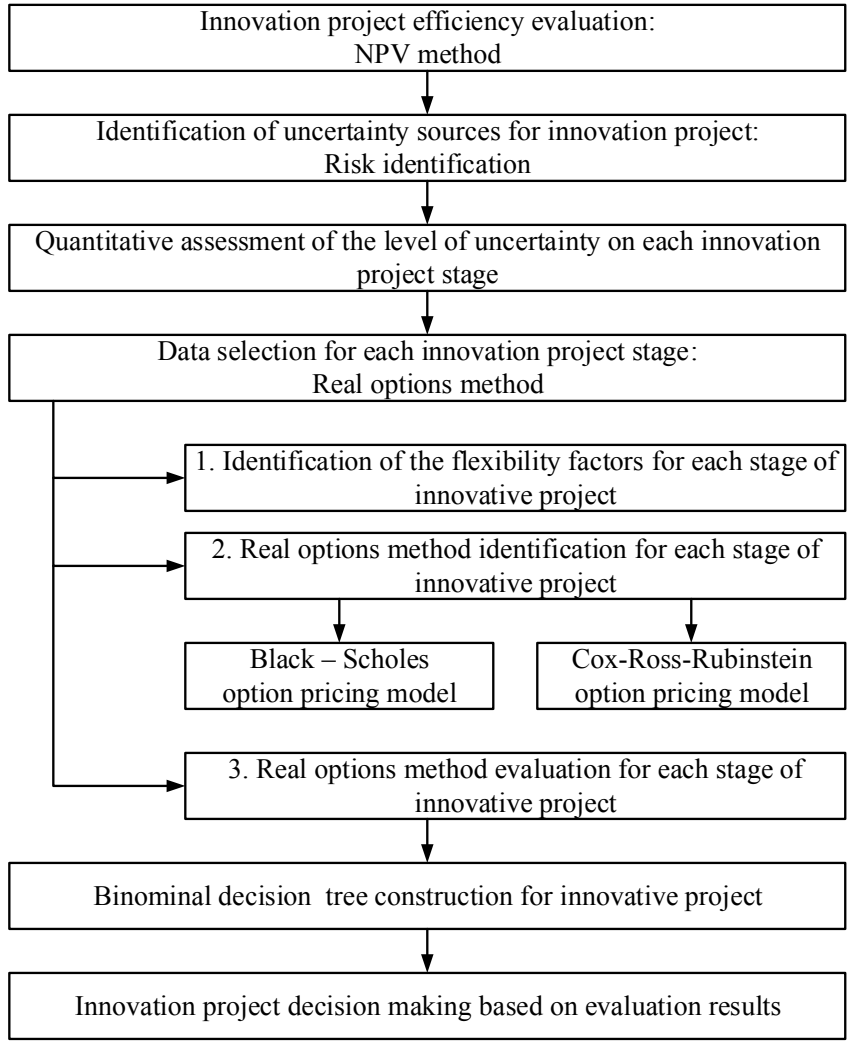

Fig. 2. Modeling algorithm development of the innovative project effectiveness evaluation based on real options in the form of a binary tree.

project managers can observe the resolution of uncertainties, such as the success of initial research. Then they can proceed to the operation stage (multi-stage), if the initial results are promising or otherwise suspend the innovation project (multistage)

Any investment innovation project should be justified by technical and economic calculations. These features lead to the analysis of innovative projects from the perspective of multi-stage and multi-scenarios - dividing the implementation of the project into logical stages, and the transition to each subsequent stage of the project is directly related to the effectiveness of the previous one, and each stage can result in both success and loss. The project decision-making management makes the choice at the end of each stage: to develop, expand, grow up, defer or abandon investment in the innovation project, taking into account the stages and uncertainties that affect the assessment of the overall economic efficiency of the project and managerial flexibility [12], [13].

\section{CONCLUSION}

Thus, the study presented the possibilities of computer program modeling to develop methodological support, economic and mathematical tools for managing and evaluating the effectiveness of innovative projects based on binomial models of real options [14].

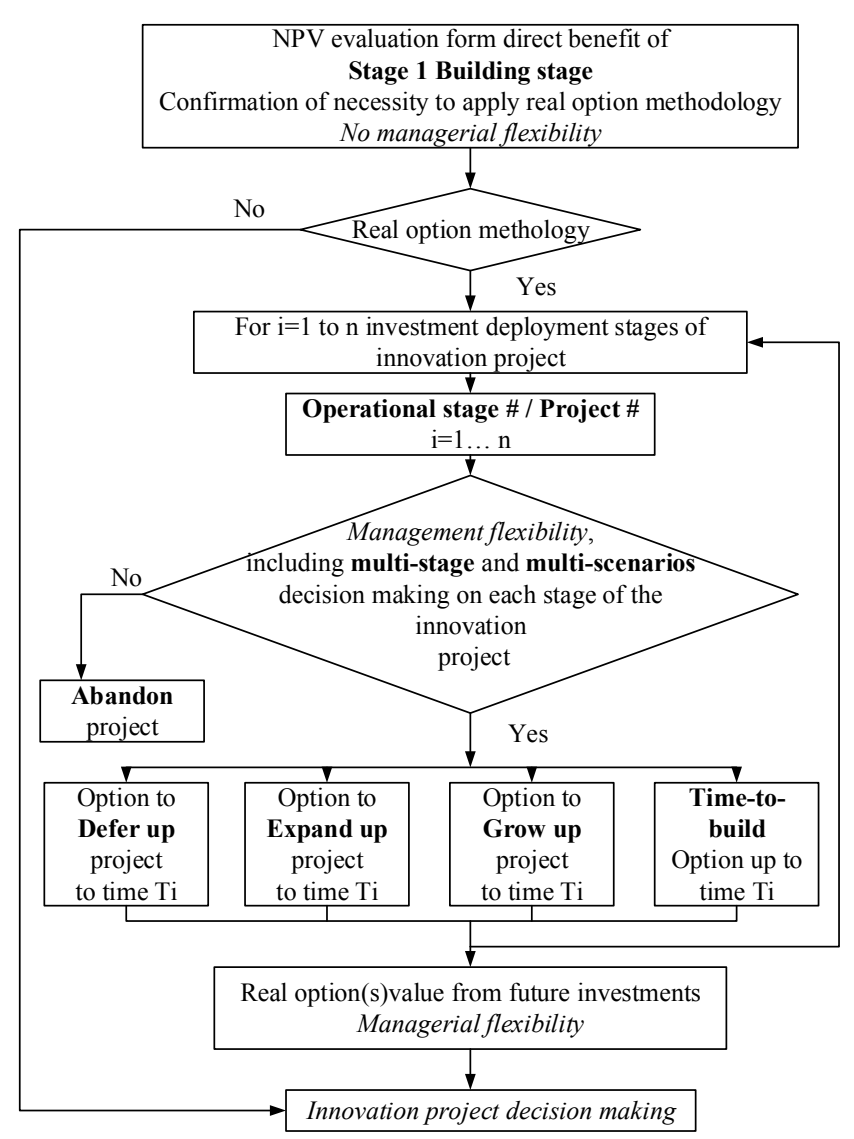

Fig. 3. Computer program algorithm development of the innovative project decision making based on real options methodology.

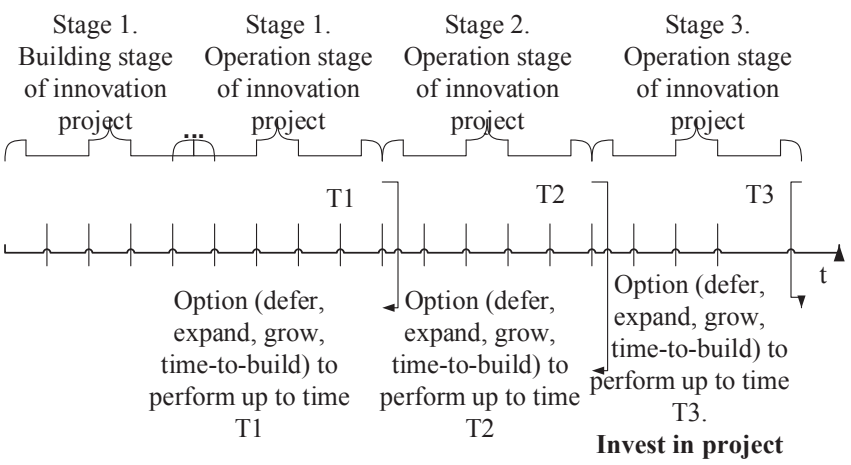

Fig. 4. Time-line development of the innovative project decision making based on real options methodology. 


\section{ACKNOWLEDGMENT}

General calculation of the effectiveness of investment projects should be carried out on the basis of cash flows. At the same time to detail the goal of the innovation project is to show what actions, in what way, at what time and with what expected result should be carried out in the process of project implementation. It is also necessary to prove the market viability of the project - justify the presence of demand for the project product, the prospects for market development, the competitiveness of the business being created and the availability of reliable ways to enter the market. In addition, it is required to give a fairly reliable forecast of sales volumes of goods and services of the project.

The technical feasibility of the innovation project is also important, because the project should be completed on time, the cost should not exceed the estimated level, and the productivity and quality of the innovation products should meet the design conditions.

Calculation the economic efficiency of the innovation project means using the financial model to show that under given market and organizational and technical conditions, the innovation project will generate enough cash flows to satisfy the requirements of the main investors for the level of profitability.

To assess the effectiveness of innovative projects, management has demanded various principles and methods for evaluating innovative projects that allow for multi-criteria and multi-scenarios analysis and substantiate management decisions on the choice of projects for implementation in order to minimize risks.

As a result of the study, computer program algorithm of future software package for evaluating the effectiveness of innovative projects based on binomial models of real options in modern programming languages in the form of a binary tree are presented.
The reported study was supported by Russian Foundation for Basic Research, project "Development of economic and mathematical tools for managing and evaluating the effectiveness of innovative projects based on binomial models", No 18-010-00793.

\section{REFERENCES}

[1] Myers, St., "Determinants of corporate borrowing," Journal of Financial Economics, vol. 5, 1977, pp. 147-175.

[2] Makarova, E. L., "Development of economic and mathematical tools for managing and evaluating the effectiveness of innovative projects based on binomial models," Herald of Adygea State University. Series Economy, vol. 3, no. 225, 2018, pp. 271-278.

[3] Limitovsky, M. A., Lobanova, E. N., Minasyan, V. B. and Palamarchuk, V. P., "Corporate financial management," Yurait Publ., Moscow, 2014, p. 990.

[4] Black, F. and Scholes, M. "The Pricing of Options and Corporate Liabilities," Journal of Political Economy, vol. 81, 1973, pp. 637-659

[5] Hull, J. C., "Options, Futures, and Other Derivatives," 8th edn. Prentice Hall, Upper Saddle River, New Jersey, 2012, p. 568.

[6] Krukovsky, A. A., "The model of real options in investment analysis," Transactions of ISA RAS., vol.30, 2007, pp. 95-112.

[7] Cox, J., Ross, S. and Rubinstein, M., "Option pricing: A simplified approach," Journal Financial Economics, vol. 7, 1979, pp. 229-263.

[8] Rogova, E. M. and Yarygin, A. I., "Application of new methods for evaluating innovative projects: a model of weighted polynomial value of a real option," Innovations, vol. 7, 2011, pp. 104-112.

[9] Firsova, A. A., "The main factors of uncertainty in assessing the effectiveness of innovative projects using the real options method," Innovative activity, vol. 1 , no. 48, 2019, pp. 78-84.

[10] Limitovsky, M. A., "Investment Projects and Real Options in Emerging Markets," 5th ed., Yurayt Publishing House, Moscow, 2011, p. 486.

[11] Angelou, G. N. and Economides, A. A., "Flexible ICT investments analysis using real options," International Journal of Technology, Policy and Management, vol. 5, no. 2, 2005, pp. 146-156.

[12] Trigeorgis, L., "Real options and interactions with financial flexibility," Financial Management vol. 22, no. 3, 1993, pp. 202-224.

[13] Firsova, A. A., "Main Characteristics of Real Options in the Implementation of Innovation Projects," Izv. Saratov Univ. (N.S.), Ser. Economics. Management. Law, vol. 18, no.2, 2018, pp. 162-168.

[14] Brandão, L. E., Dyer, J. S. and Hahn, W. J., "Using Binomial Decision Trees to Solve Real-Option Valuation Problems," Decision Analysis, vol. 2, no. 2, 2005, pp. 69-88. 